\title{
Young children's protest: what it can (not) tell us about early normative understanding
}

\author{
Johannes L. Brandl ${ }^{1}$ • Frank Esken ${ }^{1}$. \\ Beate Priewasser $^{2}$ - Eva Rafetseder ${ }^{3}$
}

Published online: 19 September 2015

(C) The Author(s) 2015. This article is published with open access at Springerlink.com

\begin{abstract}
In this paper we address the question how children come to understand normativity through simple forms of social interaction. A recent line of research suggests that even very young children can understand social norms quite independently of any moral context. We focus on a methodological procedure developed by Rakoczy et al., Developmental Psychology, 44(3), 875-881, (2008) that measures children's protest behaviour when a pre-established constitutive rule has been violated. Children seem to protest when they realize that rule violations are not allowed or should not have happened. We point out that there is more than one possible explanation for children's reactions in these studies. They could be due to (1) disobeying an authority, (2) an inability to follow a rule, or (3) the violation of an empirical expectation due to the mismatch between statement and action. We thus question whether it would still count as an indicator for normative understanding if children responded to aspects of the game other than the violation of a constitutive rule and conclude that the protesting behavior, when taken in isolation, does not suffice as evidence for normative understanding.
\end{abstract}

Keywords Social cognition - Norm understanding - Development of social norms · Normative protest $\cdot$ Norms and conventions

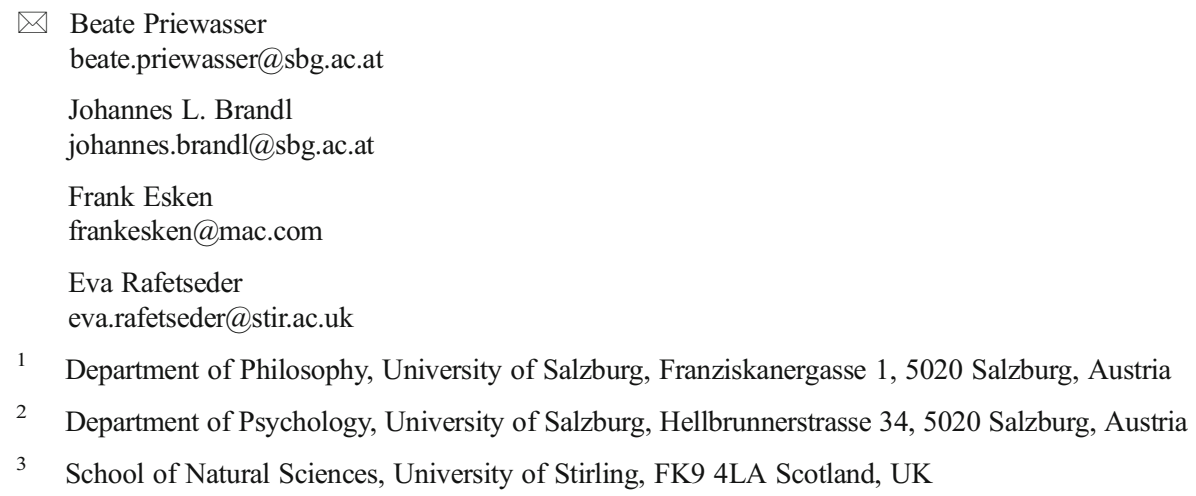


In view of the fact that human social life is infused with norms it is not surprising that an understanding of the content of norms plays a major role in children's cognitive development. A growing body of developmental studies suggests that even toddlers possess a normative awareness that manifests itself in different settings, notably in conventional and in pretend games, with various competences, for example, dealing with property rights, with artefact functions, or with various kinds of entitlements. The main evidence in these studies is that children show signs of protest, presumably, in reaction to the violation of a rule. But how strong is this evidence for normative understanding? As we will argue in this paper, the way one interprets these data mainly depends on what counts as normative protest and what does not. This is much less straightforward than it might appear.

Questions of normativity relate to what ought to be. Already at this starting point the consensus about "normativity" reaches its limits. Some would argue that norms and normative understanding arise exclusively in a social or moral context, while others think that normativity has a much broader meaning including all kinds of practical reason. ${ }^{1}$ Consider an individual action like taking the umbrella before leaving the house; if we consider this to be an action which includes a normative dimension (i.e., I should/ought to take the umbrella otherwise I will get wet), then every action which is done for a reason, that is, every intentional action, would be guided by a norm of rationality. Similarly every judgement possesses a normative dimension, if normativity is no more than the possibility of being right or wrong. In this very wide sense of practical and theoretical rationality, understanding normative constraints requires no social or moral context. It basically comes down to the recognition that a certain course of action will contribute - or not - to reach a certain goal and that one's judgement can be correct or incorrect. Studies about normative understanding often rely on such a broad notion of normativity. For instance, in Kenward (2012) 3- to 5-year-old children objected significantly more to a puppet acting irrationally (e.g., using a black marker instead of cloth to polish jewels) compared to a puppet violating a convention (e.g., incorrectly colour-sorting jewels) and a puppet not over-imitating (e.g., not unnecessarily knocking the jewel before replacing it). While this shows that children clearly understand when an agent does not use an appropriate tool to reach a certain goal, the normativity involved in such understanding seems to concern only very basic norms of practical rationality.

For the purpose of this paper, we will mostly set aside this broad notion of normativity (we will come back to it towards the end of the paper). The experiments on early forms of understanding normativity in young children, which are in the focus of this paper, concern norms emerging in a social context. Norms in this narrower sense are rules and regularities to which one ought to conform because other people demand it. Accordingly, we will argue that social norms have to fulfil the following two conditions: 1. The question for the agent to fulfil a social norm is not what he needs to do in order to reach a goal (i.e., it is not a question of individual practical rationality); the question is what he should do to fulfil what others expect from him (i.e., a question of what one might call social practical rationality). 2 . The fulfilment of social norms is realized by the subject's recognition of certain rules which are in place in a situations of a given kind; this means that it is not enough that social norms are instantiated by an

\footnotetext{
${ }^{1}$ See the contribution by Johannes Roessler and Josef Perner in this volume.
} 
authority that arbitrarily (i.e., rule-independently) forces the subject to behave in a certain way in situations of that kind. Examples illustrating these two conditions will be provided as we go along.

Our main question then will be how children come to understand social norms based on conventions through social interaction. We will focus on Hannes Rakoczy's and colleagues recent publications on children's protest behaviour when normative boundaries are transgressed, but we think that our line of criticism can be extended to other studies on norm transgressions whether they test spontaneous reactions or are interview-based. There is one other line of research in early normative understanding that we are not directly addressing here: Studies on children's ability to distinguish moral norms from conventional norms (Turiel 1983; Nucci 2001). The reason why we set these studies aside is that Rakoczy's work promises to shed light on early forms of normative understanding that is independent of children's sensitivity to moral issues. First of all, it is questionable whether children at the age of Rakoczy's studies already grasp the distinction between conventional and moral norms. But even if this turned out to be the case, it is not of our concern here. We are interested in whether and how it can be shown that an understanding of socially implemented norms develops outside a moral context.

In the first part we will summarize the experimental set up which we will refer to as the "protesting paradigm" (section 1), followed by a survey of existing data and highlighting critical features that have not been investigated yet. As we will explain, children's reactions in these experiments could also be due to disobeying an authority, the inability to follow the rule or the violation of an empirical expectation due to the mismatch between statement and action (sections 2-4). These alternative explanations cast doubts on protest being a reliable indicator of normative understanding. Based on these concerns, we present a new study in which additional triggers for protest were eliminated and children's spontaneous intervention responses to a pure rule violation was investigated (section 5). In the remaining part of this paper we will address two basic objections to our procedure. One objection is that, if one removes the vagueness of the term 'normativity', the methodological difficulties that we have been concerned with will disappear. In response to this objection we show that new problems for interpreting the empirical data will arise when adopting a more stringent notion of normativity like the one suggested by Cristina Bicchieri (section 6). The other objection is that one could escape the methodological worries by choosing a thin notion of normative response that applies whenever behavior is conceived as 'inappropriate'. If such a broad understanding of norm violations includes a basic sensitivity to unpleasant behaviour or to actions that lack any form of rationality then this would trivialize the protesting paradigm. We therefore agree with Rakoczy that using experimental data to track children's normative understanding presupposes that one places clear limits on the concept of normativity (section 7). Finally, in section 8 , we tentatively propose a more inclusive approach that should also take into account the special role of authorities in this line of research.

\section{The protesting paradigm}

In a seminal paper, Rakoczy et al. (2008) proposed a new way for testing children's early understanding of norms. A basic idea underlying their approach is that norm 
violations may be perceived as a reason for protest, irrespective of what kind of norm is at stake. Hence, protesting could be a reliable indicator of normative understanding also outside a moral context.

The protesting paradigm, as we have called it, measures awareness of normativity via children's reactions to a puppet's violation of a constitutive rule in a conventional game. The children tested are between 2 and 3 years old. They are first familiarised with two novel actions, for example:

Action 1: putting a stick into a small piece of wood and using this newly built tool to push a block across a Styrofoam board into a chute (A1).

Action 2: lifting the Styrofoam board and letting the block glide into the chute (A2).

In the experimental condition, these two actions are presented in the context of a game, labelled with a novel verb (e.g., daxing); A1 is presented as the game's action ("This is daxing. Now I am daxing!"), while A2 is announced to be a mistake ("Oops! This is not how daxing goes!"). In the control condition, A1 and A2 are presented outside a game context, being just two different possible actions ("I can do this!"). In the test phase, a hand puppet (e.g., Max) appears and announces what he is going to do. He either says "I'm gonna dax now!" (experimental condition) or "I'm gonna show you something!" (control condition). In both cases Max then goes on to do A2 and children's responses to the puppet's performance are recorded. Their reactions were coded as indicating normative awareness whenever normative vocabulary was used, for example, "no, it doesn't go like this". ${ }^{2}$ These remarks are contrasted with imperative responses that are presumed to constitute indirect, but inconclusive evidence for normative understanding, e.g., "no, not in this hole".

It is hypothesised that children who are aware of the normative structure of the game in the experimental condition would protest against the puppet's performance of action A2, finding this behaviour incorrect. No such reaction is expected in the control condition in which A2 does not constitute a mistake. These expectations seem to be confirmed because 3- and to some degree 2-year-olds showed more protest, in particular normative protest, in the experimental condition compared to the control condition.

In several follow-up studies, the basic structure of the protesting paradigm was used in order to investigate different aspects of children's normative understanding (for an overview see Table 1). Different types of norm violations (e.g., violation of explicit game rules, implicit pretence rules, artefact functions, moral norms, or property rights) were compared to matching scenarios with no such violations (e.g., the puppet doesn't engage in the normative context, follows the norm, uses objects in the usual way, destroys an unassigned, or self-possessed object). In all these cases, children consistently displayed significantly more protest reactions against norm violations. A certain amount of protest, even normative protest, was found in control conditions as well. And still, since the amount of protest was significantly reduced in matched scenarios, the

\footnotetext{
2 There is some variation in the responses that are put into this category. In some studies, reporting and tattling to the experimenter are also counted as normative responses, as well as attempts to teach the puppet, demonstrations of the correct action, questioning the puppet's behaviour, and referring to rules or emotional states.
} 


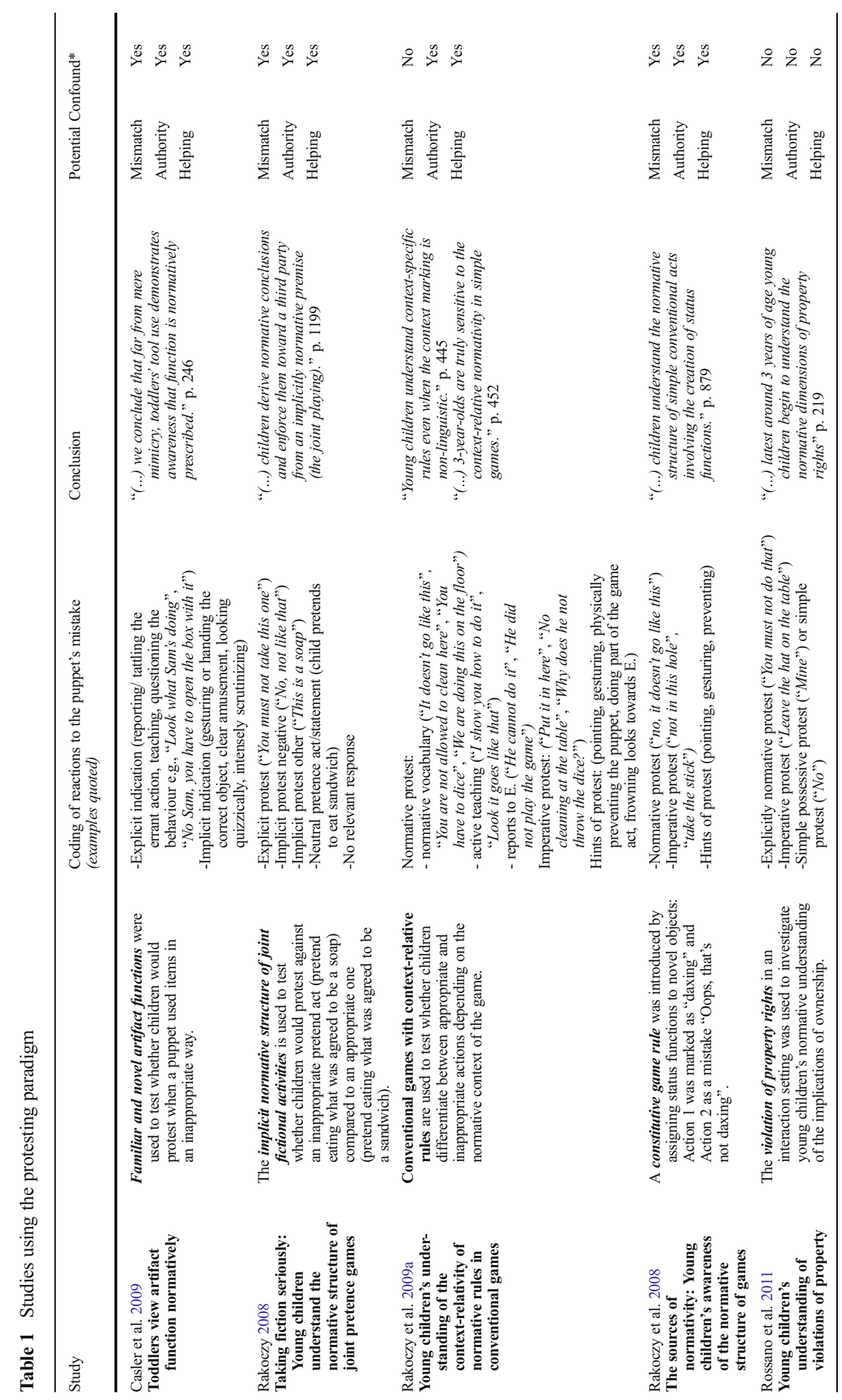




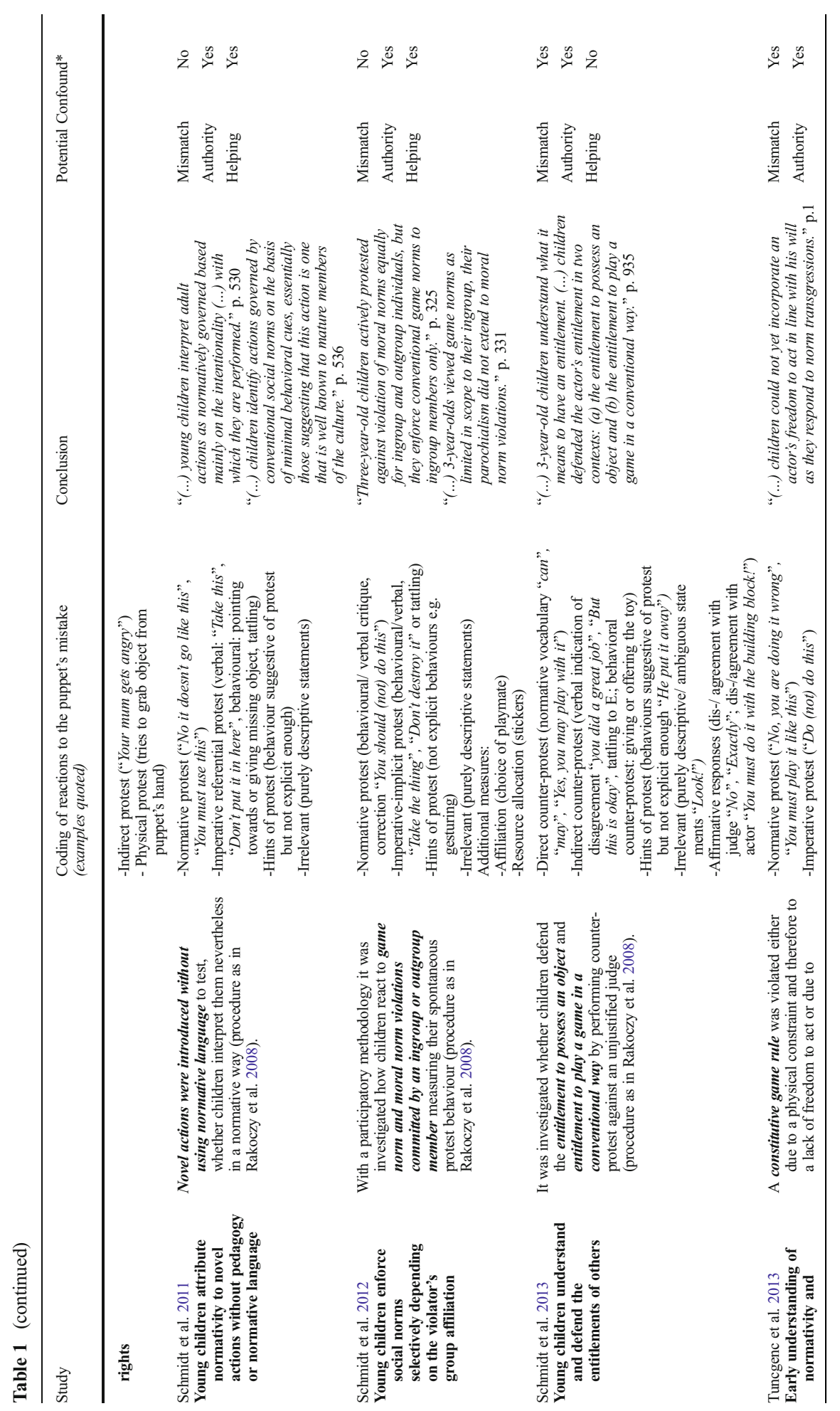




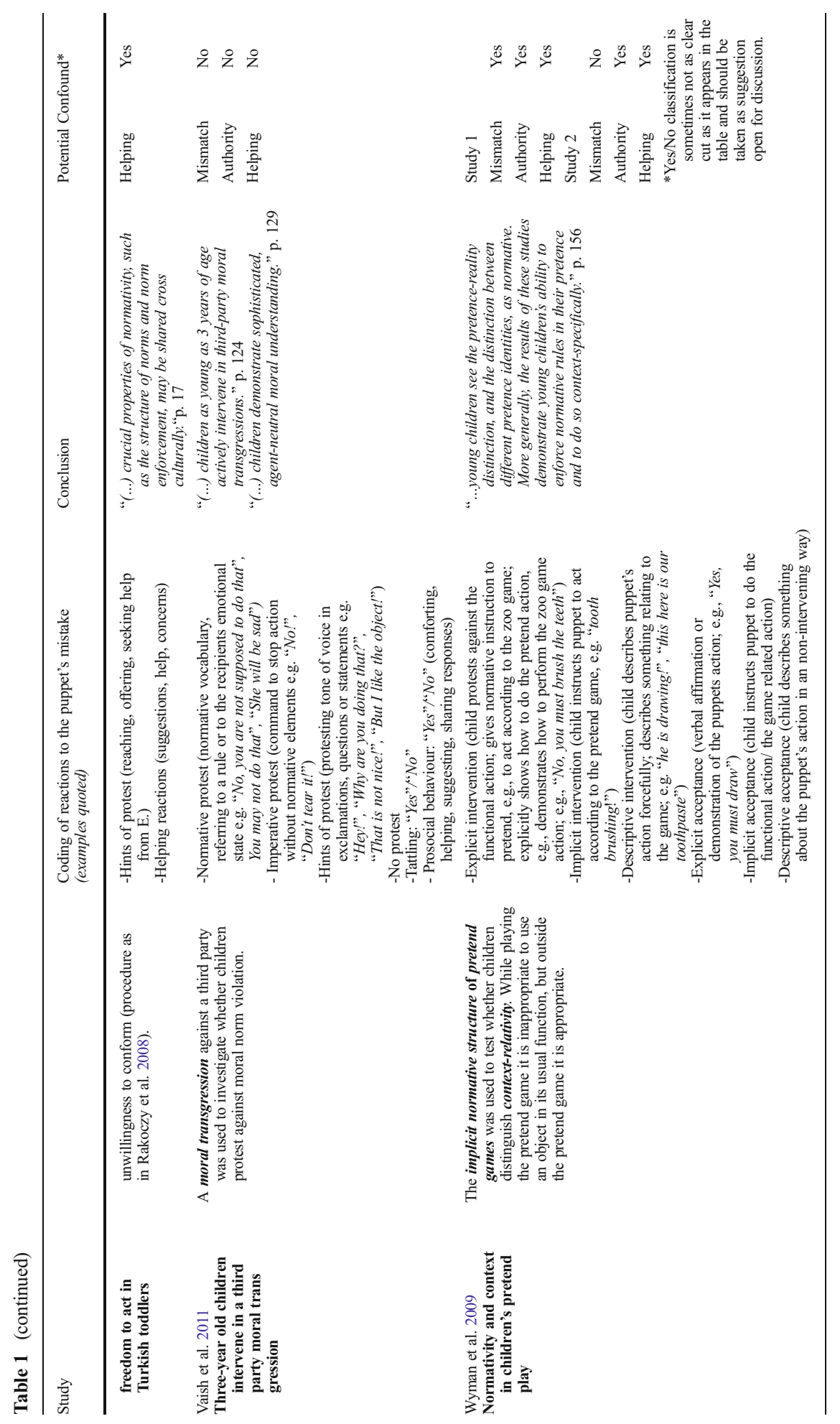


general conclusion that children's protest behaviour is a reliable indicator for understanding the normative structure of games seems warranted.

While we do not want to deny that the reported reactions may be indicative of a general awareness that something has gone 'wrong', or that something 'wrong' has been done, it would be premature to call these responses a 'normative protest' merely for this reason. As we mentioned before, we feel uneasy about speaking of normativity in such an undiscriminating way, and we will explain our reservations in more detail later in section 7. The experiments of Rakoczy do not rely on such a broad notion of normativity. This is why they give rise to a number of pertinent questions that we want to take up in the following three sections. These questions concern: a) the novelty of the introduced rule, b) the three-way interaction between experimenter, puppet, and child, and c) the coding of children's reactions and whether these reactions might address the mismatch between announcement and action.

\section{Questions about constitutive rules}

The protesting paradigm has its philosophical foundations in John Searle's theory of social ontology and especially in his notion of constitutive rules. Constitutive rules are rules that do not only regulate but also create the very possibility of certain activities, like for example the rules of chess create the very possibility of playing chess (see Searle 1995, p. 27). For Searle any form of normative behaviour is bound to the instantiation of constitutive rules and the so-called status function these rules create. Searle writes: "(Non-human) animals can impose functions on natural phenomena. Consider, for example, the primates that use a stick as a tool to get bananas that are out of reach. And some primates have even developed traditions of agentive functions that are transmitted from one generation to the next. Thus, most famously Imo, a Japanese macaque, used water to get the sand off her potatoes [...]. Thanks to Imo, today potatowashing in salt water is an established tradition which infants learn from their mother as a natural adjunct of eating potatoes. [...]. But the truly radical break with other forms of life comes when humans, through collective intentionality, impose functions on phenomena where the function cannot be achieved solely in virtue of physics and chemistry but requires continued human cooperation in the specific forms of recognition, acceptance, and acknowledgment of a new status to which a function is assigned." (Searle 1995, p. 40)

Status functions are instantiated through constitutive rules which Searle characterizes by the formula "X counts as $\mathrm{Y}$ in $\mathrm{C}$ ". The physical object $\mathrm{X}$ (for example a piece of paper) acquires a new status (for example to count as money) to which a function is attached by way of collective intentionality, where the status and its accompanying function go beyond the sheer brute physical functions that can be assigned to physical objects. (p. 44)

The important point about this formula is that constitutive rules are rules in which the $\mathrm{Y}$ term assigns a new status that the object does not already have just in virtue of satisfying the $X$ term (p. 44). This additional constraint is not automatically satisfied, as Searle makes clear with the following example: "objects that are designed and used to be sat on by one person count as chairs". In this case satisfying the X term is already sufficient for satisfying the Y term, due to the definition of the word "chair". Therefore 
such a rule does not add anything but a label. The point is worth emphasizing here because in the examples used to test children's understanding of normativity it may also seem as if only a new label is introduced for an arbitrary movement. But that is not the case. In these instances children do not only learn what to call a particular action, they also learn the action itself. The constraint that Searle places on constitutive rules can therefore be generalized as the requirement that such rules should create new types of activities, or assign a new meaning to a specific moment of time, for instance, by declaring it to be the right time to go to bed. The conventional agreement that is needed to establish such rules does not merely concern the use of a certain label, but facts in the world.

Some interpreters of Searle understand his distinction between regulative und constitutive rules differently, assuming that only the former have a regulatory function. Another question is whether one should tie the normativity of rules to regulatory functions or to a "person or body with the power to prescribe (proscribe) certain behaviour" (see Brinck in her contribution in the same issue of this journal entitled "On the early development of social norms and constitutive rules"). Since we cannot pursue these issues here, we simply put on record that we understand the distinction in such a way that constitutive rules also regulate the new type of behaviour that ensues from following these rules, and that constitutive rules therefore can also have a normative force. Brinck does not deny this latter point, but insists that "it is the policymaker who ascribes normative force via policies and guidelines, whereas the normative force of the constitutive rule is indirect, or derivative." (see Brinck 2014.) In her view, this point alone undermines Rakoczy's experimental paradigm. We prefer to be more cautious in this respect. After all, the protesting behaviour exactly does what Brinck asks for: children demonstrate that they do not only understand the rules of the game, they are also ready to enforce them. At least this is the impression one gets when they intervene, sometimes by even physically stopping the puppet from doing A2 (e.g., lifting the Styrofoam board).

Why, then, do we suspect that the protesting paradigm might nevertheless run into troubles? Prima facie it would seem that children could learn about mechanisms to enforce rules also by learning how rules that merely regulate existing behaviour are socially enforced. This becomes clear if we again take the case of moral transgressions. In a recent study by Vaish et al. (2011), 3-years-olds frequently protested when a moral transgression occurred. No constitutive rules had to be introduced to create a rule violation. The scenario involved two hand-puppets and the child, all three drawing on separate sheets of paper. Upon finishing, the child's drawing was placed on the floor and the two puppets' drawings were placed on the table next to a blank sheet of paper. Then one puppet left the room. Subsequently, the remaining puppet announced that she did not like the other puppets' drawing (harm condition) or the blank sheet of paper (control condition) and that she was going to tear it apart. Then she destroyed the drawing (experimental condition) or the blank sheet (control condition). Significantly more 3year-olds protested in the harm condition. Their protest was also more pronounced (see Table 1). Moral transgressions therefore provide a clear case in which protest responses are triggered quite independently of whether or not children learn a new constitutive rule.

Now, we have accepted the following two assumptions of the protesting paradigm: (1) there is no normative understanding without an awareness of rules, and (2) there can be normative understanding without grasping rules of morality. From these two 
assumptions it does not follow, however, that grasping a new constitutive rule is both necessary and sufficient for understanding a non-moral type of normativity. It may not be necessary because there may be purely regulatory rules outside the moral domain, and it is not sufficient because children may grasp a constitutive rule without grasping its normative force.

\section{Questions about social interaction}

A characteristic feature of the protest paradigm is the three-way interaction between the experimenter, the puppet (directed by a puppeteer), and the child. In the experimental condition of the standard paradigm the experimenter acts in the position of an authority that introduces a new rule/game. In the control condition the experimenter is exploring the game materials and suggesting two possible ways how to handle them but does not introduce a rule. As a role model, he determines the context and children may perceive both conditions in a deontic way. According to Cummins (1996, p. 823) behaviour that adheres to conditional deontic rules asks children to "determine which actions are permitted, obligated, or prohibited, and under which conditions." Deontic rules are therefore clearly distinguishable from rules of practical rationality that only express what needs to be done to reach a certain goal. Hence, children's protest in the daxing studies against the puppet's action A2 could be interpreted as a protest against the puppet disobeying an authority. In the control condition the puppets' action is in line with the context introduced by the authority and therefore children do not need to enforce the rule. Rakoczy et al. (2009a, p. 449) supports this hypothesis by pointing out that children might "rely on [experimenter] E1 in enforcing normative rules, or even reason as follows: 'She (E1) does not object to this, so it must be according to the rules after all...'”' Indeed, in our replications of the daxing study we observed that many children spontaneously looked to the experimenter, but as they were ignored they started to intervene.

Other support for such an interpretation comes from a study by Schmidt et al. (2011). Using the original protesting paradigm the experimenter performed A1 without any explicit labelling of the action either in a "recognizing" context ("I look at what I have here. I will do that now, yes") or in an "inventing" context ("Huh, what's that? Hmm, well"). Additionally, it was manipulated whether or not the experimenter used ostensive cues (e.g., calling the child by name) to communicate a pedagogical intention. When the puppet subsequently performed A2, children protested significantly more often in the recognizing condition, irrespective of the experimenters pedagogical intention. The mere observation of an adult, either performing an obviously wellestablished action or inventing a new action, had a significant influence on children's reactions to the puppets' performance. They enforced the recognised action that seemed requested in that situation rather than the invented action.

If children actually interpret the rule 'If one daxes, one must do A1' as a deontic rule and adopt the role of the authority to enforce it, this might explain why normative protest occurs more often in the experimental condition than in the control condition of this and many other studies (see Table 1). But whether such an interpretation is justified remains to be seen. After all, children could interpret the rule also in a non-normative way: "If one daxes, one does A1", which equals: "Daxing means to do A1". 


\section{Questions about coding and verbal announcement}

In this section we address the issue how children's verbal and nonverbal reactions have been coded and categorised. As mentioned earlier, the explicit use of normative language is seen as the most salient feature indicating that children interpret an action as the violation of a norm (e.g., "no, it doesn't go like this", "you must (not) do it like this", "you do it wrongly", "you are not supposed/allowed to do that", "you have to do it like this", "you may/ may not do this", "you should not do this"). A substantial amount of children in each study reacted by giving the puppet imperative instructions (e.g., "no, not in this hole", "take the stick", "put it in here", "not like that", "do (not do) this"). Since these remarks do not explicitly use normative language, we agree with Rakoczy et al. that they provide no conclusive evidence for normative awareness, but should rather be interpreted as attempts to correct a mistake. Furthermore, a third category of responses called "hints of protest" is often introduced which includes nonverbal pointing, gesturing, offering, physically intervening, looking at the experimenter as well as neutral descriptions, statements, or questions.

Clearly, this coding procedure is a delicate process, since we cannot be sure what an exclamation such as "It does not go like this!" actually means. It could be interpreted (1) as normative protest, following Rakoczy et al. (2008), carrying the meaning that the puppet is unwilling to perform A1 or (2) as a correcting response, carrying the meaning that the puppet is unable to perform A1. Since both actions-A1 and A2 - have been shown to be okay in the control condition, A2 does neither elicit a protest response (the puppet is not unwilling), nor a helping or correcting response (the puppet is not unable). ${ }^{3}$

The study by Tuncgenc et al. (2013, study 2) supports this idea. Two- and threeyear-olds observed how a puppet was unable (e.g., the puppet's hands were bound together) or unwilling (same as the experimental condition in Rakoczy et al. 2008) to carry out A1. In the physical constraint condition the puppet attempted to carry out A1 (e.g., trying to put the wooden stick into the piece of wood) whilst uttering "Oh! I can't do that. I cannot hold the stick". After two failed attempts the puppet performed A2, announcing "I daxed!" Children showed an increased helping behaviour (e.g., expressing concerns towards the puppet; making suggestions how to solve the situation). Notably, what is traditionally coded as normative protest was not decreased in this condition compared to the traditional experimental condition.

With this finding we run into several problems. If we assume that the same behaviour (i.e., normative protest) can be shown for different reasons in different conditions (to enforce a constitutive rule in the daxing condition; to help/correct in the physical constraint condition), it alerts to a wider problem: normative protest may not be selectively shown for norm violations. Conversely, if we assume that the same behaviour is shown for the same reason in different conditions (either to help or to enforce a constitutive rule in both conditions) it may suggest that children are confused about the puppet's intention (they take the puppet to be unwilling or unable in both conditions). We do, however, not want to claim that children are not sensitive to the difference between unwillingness and inability at that age. In fact there is a large body

\footnotetext{
${ }^{3}$ It is important to note that the original study included a warm-up phase in which the children were 'practised' in critiquing and correcting the puppet when making instrumental mistakes. This by itself could have led the children to believe that the puppet is unable to do things correctly.
} 
of research showing that even infants and non-human primates are sensitive to whether an actor deliberately failed or whether he tried without success (Behne et al. 2005; Call et al. 2004; Legrain et al. 2012; Marsh et al. 2010; Philipps et al. 2009). It may just be that the original paradigm is not clear enough about the puppet's real intention. Importantly, this does not explain why several studies have found a difference between control and experimental conditions but it is an unspecified factor that introduces variance in children's reactions and hampers a clear interpretation of the data.

If protest behaviour is shown for the same reason in both conditions it seems more likely that children conceived the puppet as being unable to do A1 rather than unwilling since the puppet makes an effort to show A1 in the physical constraint condition. This could mean that there is no real difference between normative remarks and imperative advice in the daxing game either. Both could be responses to the violation of a principle of instrumental rationality rather than a social or a conventional norm. But even if children understood the different intentions of the puppet and reacted accordingly, then the Tuncgenc study would still cast doubts that normative protest is a sensitive measure. Or it would force us to say that a helping/correcting response also expresses adherence to a norm, namely the norm to help those who need it.

The same reasoning applies also to the question whether children might protest against the mismatch between what the puppet announces to do and what she actually does. In the procedure of the daxing game such an inconsistency occurs in the experimental condition but not in the control condition. Children might find this irritating, particularly if the puppet seems to be fully aware that what she is doing is not the "correct" action, but nevertheless insists to have daxed. ${ }^{4}$ Toddlers' protest in these and similar studies could be interpreted as expressing an irritation about the mismatch between saying and doing (please note that other studies found normative protest despite the procedure not containing an inconsistency between announcement and action, for details see Table 1).

This suggestion appears plausible as by the age of 16 months children start to look longer, show signs of irritation, and correct the speaker when adults use false labels for common objects (Koenig and Echols 2003). Rakoczy and Tomasello (2009) tested children's sensitivity for direction of fit in speech acts and found, when an assertion did not fit reality or a directive was not followed, 3-year-olds verbally corrected the statements accordingly (e.g., "No, this is not...", "No, you are not..."). In the daxing paradigm the puppet's stated intention may implement an empirical expectation about what will or should happen next. When the continuing scenario does not meet this expectation, children react to this inconsistency and what is interpreted as protest, might be their attempt to either change reality in order to fit the assertion ("You have to do it like that!") or to correct the assertion in order to depict reality ("That's not daxing!").

Once again, it remains unclear how children's sensitivity to such a mismatch should be interpreted. Perhaps they simply register the mismatch and feel irritated about it. Perhaps they think that acting contrary to one's own declarations constitutes a violation of a norm. We have therefore conducted a new study that specifically explores the impact of the mismatch in an experimental manipulation.

\footnotetext{
${ }^{4}$ It would be interesting to see when the toddlers' protest in the study of Tuncgenc et al. (2013, study 2) actually started, before or after the announcement. If our assumption is correct, protest should have started more often after the puppet's announcement.
} 


\section{Traffic light study}

So far we have pointed out that there is more than one possible explanation for children's reactions in the daxing-paradigm and that it has to be discussed whether it would still count as an indicator for normative understanding if children responded to aspects of the game other than the violation of a constitutive rule. We argued that children's reactions could also be due to the puppet disobeying an authority, the puppet's inability to follow the rule or the violation of an empirical expectation due to the mismatch between statement and action.

As a consequence, the aim of our first study was to eliminate any additional triggers and test for children's spontaneous intervention responses to a pure rule violation. Instead of introducing a new constitutive rule in a game, we used a norm that children were already familiar with. The set-up contained a small model of a yard that was bordering a road with a zebra crossing and a traffic-light showing either a green or a red man. Each child sat at a table with an experimenter who acted out the story with little toy-figures (a male adult puppet and two child puppets were introduced as father and children). Each condition started with the male puppet explaining the traffic light rules to his children. The children then left the scene while the father puppet stayed next to the traffic light. Then one child at the time returned and announced: "I am going to cross the road". The story continued slightly different depending on the condition: In the norm following condition the puppet crossed the road at the green light; in the norm violation condition it crossed at the red light. We also included a mismatch condition to investigate whether children would protest against the mismatch between what the puppet said she would do and what she really did. In this condition the puppet did not cross the road (although the traffic light showed a green man - hence she did not violate the norm of crossing the road at a red light) but turned around and crossed the yard instead. The mismatch consists of the announcement to cross the road and the action of crossing the yard. Thirty-seven children (14 girls) between 3 and 5 years (mean age 50 months) participated in all three conditions in a counterbalanced order. We asked five control questions to make sure that children understood the traffic light rule and the set up (two about traffic light rules with 97 and $97 \%$ correct answers and three about the actual colour of the traffic light at the beginning of each scenario with 97, 97, and $95 \%$ correct answers on the first trial). Children's spontaneous interventions while watching the scene were coded into the following categories: (1) no reaction, (2) irrelevant response, i.e., pretend cars are driving on the road, (3) minimal nonverbal reaction, i.e., smiling or looking surprised, (4) imperative terms, i.e., warning or giving advice, (5) descriptive terms, i.e., "she is crossing but it is red light", and (6) normative terms, i.e., "not allowed to", "should not", "wrong", "have to". As expected, in the norm following condition no child displayed any kind of verbal protest reaction. Unexpectedly, in the norm violation condition only five children (14 \%) displayed a spontaneous verbal reaction. One child did so in a normative way ("She is not allowed to cross!"), two in an imperative way ("But it's red!"), and two in a descriptive way ("She is crossing at red light!"). In the mismatch condition 15 children (41\%) responded verbally to the scenario with 6 children using normative terms ("Wrong! You have to cross the street!"), 7 children using descriptive terms ("But that's not the road!"), and 2 children using imperative terms ("Hey, where is the street?!"). For more details see Table 2. For testing statistical differences between conditions one would 
Table 2 Frequency of children's spontaneous reactions in the three conditions of the traffic light study

\begin{tabular}{llll}
\hline & \multicolumn{2}{l}{ Traffic Light Task Condition } & \\
\cline { 2 - 4 } & Norm Following & Norm Violation & Mismatch \\
\hline No reaction & 35 & 25 & 14 \\
Irrelevant response & 1 & 2 & 1 \\
Nonverbal reaction & 1 & 5 & 6 \\
Imperative term & 0 & 2 & 2 \\
Descriptive term & 0 & 2 & 8 \\
Normative term & 0 & 1 & 6 \\
\hline
\end{tabular}

have to decide which of these responses indicate normative understanding. As we have argued, we think it is artificial to apply a coding system based on the use of normative terms and therefore prefer presenting descriptive data.

A critical difference between the "daxing task" and the "traffic light task" that could explain children's reluctance to intervene in the latter study is the task format. Unlike the interactive game context in the daxing study, the narrative story context of the traffic light study could be a simple explanation for children's hesitation to interfere.

To test the influence of the task format we converted the original daxing procedure into a miniature scenario which was acted out to children in the same format as the traffic light story. We used two miniature puppets and miniature materials of the daxing game (a stick and a plate to be stacked together as a tool to push a block across a board into a chute or to lift the board and let the block glide into the chute without using the tool) and followed exactly the wording and procedure of the original study. Thirty-two children (12 girls) between 3 and 5 years (mean age 51 months) participated in the task. Using expressions identical to the original study by Rakoczy et al. (2008), puppet 1 first declared to present a game called "daxing" to puppet 2 and then demonstrated action A1. After showing one correct action (A1), one failed attempt (A2) and one more correct action (A1), puppet 1 is placed on a miniature chair turning away from the scene. Next, puppet 2 announces "Now I am going to dax" but acts out the failed attempt (A2) twice. As our main interest was to compare the amount of children who protest in the experimental conditions of the original interactive context and of our new story context, it was sufficient to present each child with only one experimental condition. Children's reactions were coded using categories as suggested by Rakoczy et al. (2008): no protest (12 children, $38 \%$ ), hints of protest ( 3 children, $9 \%$ ), imperative protest ( 2 children, $6 \%$ ), and normative protest (15 children, $47 \%$ ). In Rakoczy et al. (2008) children were presented with two experimental conditions and only the mean sum score, not the exact distribution, is reported. The mean sum score of the 3-year-olds was between 0.8 and 1 , indicating that children protested normatively on average one out of two times (given that the distribution is normal). In our study 15 out of 32 children spontaneously commented the scenario and thereby used normative phrases, indicating that the frequency of such reactions is very similar in the two studies. In addition to quantity, children's utterances were also qualitatively identical 
(e.g., "That's not how daxing goes", "You have to do it like this", "That's wrong!" or "He did it wrong!").

On the basis of these results, it can be ruled out that children refrained from protesting in the norm violation condition of the traffic light study because of the task format. Why then was such protest missing? It could be because a constitutive rule was not accompanied by additional triggers such as to step in as an enforcing authority (section 3), or because of a lack of motivation to help someone who is unable when there is a mismatch between saying and doing (section 4). Looking precisely at each of these (and probably other) factors would require disentangling what is probably a conglomerate of different normative facets. So far we can conclude on the basis of our traffic light study only that a remarkable amount of spontaneous responses can be triggered in children by observing a mismatch between a persons' statement and her action. We may also suspect that the violation of an empirical expectation can override other normative aspects of the scene. That may explain why the presence of an authority did not influence spontaneous reactions in the mismatch condition. However, the precise impact of an authority figure and its explanatory power for children's deontic norm understanding remains an open question at the moment.

\section{A problem with false positives}

The traffic light study reinforces our previous observations that the evidence provided by the protesting paradigm remains inconclusive for various reasons. It may be objected, however, that our complaints can be quite easily resolved. The problem with this paradigm may not be a methodological one, as we have surmised, but simply a conceptual problem. How should one understand the term 'normativity'? Perhaps, if one removes the vagueness of this term, the methodological difficulties that we have been concerned with will disappear. ${ }^{5}$

Let us explore this idea by invoking a proposal by Cristina Bicchieri (2006) how to precisely define the concept of a norm as it is used in the social sciences. Her conception of normativity is very much in line with our own intuitions indicated briefly at the beginning of this paper. Like Biccherie, we also think that our understanding of normativity rests on two components: there is the component of a rule that tells us what should be done, and there is a social context that enforces the rule by creating the mutual expectation that everyone will follow it. What is distinctive about Bicchierie's definition is the additional idea that preferences also play a crucial role for implementing a social norm. We do not want to comment on this element here. Therefore, the following simplified version of her definition (see Bicchieri 2006, p.11) will do for our purposes:

A certain form of behaviour that can be observed in a population $\mathrm{P}$ in situations of type $\mathrm{S}$ is governed by a norm $\mathrm{N}$, if most members of $\mathrm{P}$ (a) know that there exists a rule for situations of type $S$, (b) prefer to follow this rule if they believe that the

\footnotetext{
${ }^{5}$ We would like to thank one of the reviewers of this paper for expressing this concern when asking us to elaborate on the distinction between empirical and normative expectations.
} 
majority of $\mathrm{P}$ also follow this rule, and (c) prefer to follow this rule if they believe that the majority of $\mathrm{P}$ expects them to follow this rule.

Bicchieri calls the belief described in clause (b) an 'empirical expectation', contrasting it with the belief described in clause (c), which she calls a 'normative expectation'. For Bicchierie, these two kinds of expectations mark the difference between a mere convention and a norm. Mere conventions arise when people expect from others a certain form of behaviour (empirical expectation), while for a convention to become a norm people must believe that they are expected by others to behave in a certain way (normative expectation). In both cases, agents are motivated to follow a certain rule due to a preference that is conditional on these expectations.

Suppose we replace the vague notion of 'normativity' with this precise notion of a social norm. We still face a serious problem if we take children's protest as being indicative of their norm understanding: how do we know that their protest expresses a normative expectation and not merely an empirical expectation? They may show such protest when they are surprised or annoyed if another person breaks a rule. Once again, however, this is not normative protest unless they also recognize that a norm has been broken. Hence we would need to know when children begin to realize that other people expect from everyone else in their community (including themselves) to stick to this norm. The data about protesting that we have considered do not suffice to show this and might therefore be just "false positives". A false positive in the protesting paradigm occurs if the following two conditions obtain:

(a) a child manifests behaviour that satisfies the specified criteria for counting as a normative protest, but

(b) the behaviour of the child can be explained without attributing a normative understanding to it.

The verbal responses that children make in the 'daxing'-studies satisfy both conditions if we take the use of normative language as our criterion for classifying protest as normative. Children who exclaim, for instance, "This is wrong. You must do that!" would thus satisfy clause (a). But the use of normative language by itself does not rule out that clause (b) is satisfied too, because one can use a certain form of words with or without a full understanding of what they mean. If I say "This is wrong" in a daxinglike situation, it is clear that I thereby express a complaint about a rule-violation and that I also take this violation to be a transgression of the norm, for example, one should play according to the rules. A child who says the same, by contrast, may only express anger or dissatisfaction because she had expected something else to happen. Of course, her expectation would not exist unless the child understands the rule. But knowing the rule is not enough to understand the norm that has been broken if one does not follow this rule. If her understanding of the situation does not also include the expectation that people expect others to follow that rule and will therefore enforce it, we cannot attribute a normative understanding to this child, at least not, if we follow the conception of normativity expressed in Bicchierie's definition. And since there will be many such cases, protest behaviour ceases to be a reliable indicator of normative understanding.

At this point, one might turn the blame on Bicchierie's definition of a social norm. Perhaps her conception of a normative expectation is too demanding and one does not 
need to have second order expectations about what people expect from each other, as well as preferences that are conditional on such expectations, in order to understand the normative force of a convention. It is certainly possible that one finds a simpler way of explaining what it means to expect from others that they follow certain rules. It is therefore also possible that children develop such expectations before they become proficient mindreaders, that is, before they are able to attribute mental states to themselves and to others, and that may be sufficient to grant them a basic understanding of normativity. ${ }^{6}$ We have no reason to deny that. What our discussion should make clear, however, is that one can hardly solve our methodological problem by finding the correct definition of the concept of normativity. There is no neutral ground on which such a definition could be defended.

\section{A problem with false negatives}

The second line of reply to our criticism also begins at a conceptual level, but one that leads in the opposite direction of asking for a precise definition of normativity. Since there is no way to make the term 'normativity' precise enough to satisfy everyone, let us simply accept the term for what it is: a vague and broad notion that comprises many different aspects. Once this is accepted, we may also find it acceptable that there is no clear demarcation line between a normative and a non-normative protest.

We mentioned the possibility of using such a broad notion of normativity at the beginning of this paper and set it aside for the sake of our argument. Now we want to elaborate a little on this notion and explain the reasons that count against it. Basically, the present suggestion expands the notion of normativity in such a way that it applies whenever we can classify some action or event as 'right' or 'wrong'. There are all sorts of cases of that kind. For instance, as mentioned earlier, there is something wrong if one leaves the house without an umbrella despite the fact that one knows that it rains and that one does not want to get wet. On a broad understanding of normativity, that would be a violation of a norm of rationality. Hence one may compare such "mistakes" with normative transgressions of other kinds, including moral transgressions, for example, when one steels money although one knows that it is morally wrong to do so and wants to be a decent person. Abstracting from such cases a common notion of normativity, one might then attribute to children a basic awareness of normativity as soon as there is any evidence that children learn to distinguish between 'right' and 'wrong'. This would be normative understanding in a 'thin' sense. ${ }^{7}$

To some extent, we are sympathetic to the idea that young children first operate with an undiscriminating notion of normativity before they grasp different meanings of it, for example, the difference between a conventional and a moral norm. Yet, such a thin concept of normativity would leave us with no clue how to separate the various components involved in normative understanding of this undifferentiated kind. In particular, it does not seem helpful to run together the modality of causal necessity

\footnotetext{
${ }^{6}$ Thanks to Josef Perner for pointing out this possible interpretation to us.

${ }^{7}$ This idea is expressed by another reviewer of this paper who suspects that we subscribe to a rich notion of normativity that corresponds to an explicit understanding of social rules, and recommends instead to include also an implicit (not language based, not propositional, pre-reflective) understanding of normativity that applies to a broad range of practices, including cases of (implicit) instrumental reasoning.
} 
with a deontic modality. This is a more technical way to express the intuition that the following two aspects must not be confused: the need to do something in order to reach a certain goal, and the request or obligation that one should do something. One needs to take an umbrella if one does not want to get wet, and one should return it if one has borrowed it. The latter request emerges from a social practice, the former consideration does not. That difference remains crucial to separate normative considerations from individual practical ones.

But let us return to our methodological concern with the protesting paradigm. Intuitively, choosing a broad notion of normativity should make it easier to show that young children have some normative awareness when they protest against normviolations. Why is this move not helpful? The problem is that we are looking for a behaviour that is a reliable indicator of normative understanding. Generally speaking, a reliable indicator of some property $\mathrm{F}$ should work in two ways: it should be activated reliably when an $\mathrm{F}$ is present, and it should not be activated reliably if an $\mathrm{F}$ is missing. Accordingly, if protesting of a certain kind is to be a reliable indicator of normative understanding, there should be no protest of this kind (at least in most circumstances) if normative understanding is missing. Otherwise, the indicator fails because it produces false negatives.

In the protesting paradigm, a false negative occurs if the following two conditions obtain:

(a) a child has a basic understanding of normativity that it manifests in cases when something is done rightly or wrongly, but

(b) it shows no signs of protest (of the right kind) in conventional games or pretend games when a rule-violation occurs.

It is easy to think of cases that fit this description. Consider a baby that reliably shows signs of protest in various circumstances, for example, when her bottle is too hot, when the lid of the bottle is blocked, when the bottle does not taste sweet enough, etc. Thus even a baby can distinguish in this way between 'right' and 'wrong' and would therefore manifest some normative understanding if we were to use the term 'normative' without any restrictions. But babies do not show the right kind of protest when we present them with rule-violations in conventional games like the 'daxing'-game. Their lack of protest would therefore constitute a false negative for the explanations offered by Rakoczy et al.

One can, of course, explain away false negatives by adopting a concept of normativity that includes all this potential counter-examples. As we mentioned at the beginning, one could define normativity simply as a standard that allows us to distinguish between 'right' and 'wrong', i.e. any case in which children categorize a behaviour or event as correct/incorrect, pleasant/unpleasant, expected/unexpected, or whatever. Such categorizations can be understood like any other classification as purely factual. Simply calling something 'right' or 'wrong' does not yet make it right or wrong in a normative sense. Therefore, children might merely follow a certain pattern or regularity, when they first learn to use such terms, without grasping the deontology that we associate with such terms. Of course, if any such categorization counts as normative, irrespectively of how well it is understood, then any type of protesting behavior would be indicative of some level of "normative" understanding. In our view, this 
would mean to trivialize the protesting paradigm. We therefore agree with Rakoczy et al. that using this paradigm presupposes that one places clear limits on the concept of normativity. Thus, we see no reason to change the constraints that we have placed on this concept at the outset. Unfortunately, this prevents us from accepting a simple solution to the methodological problems we have outlined.

\section{Towards a different approach}

Even if protest behaviour cannot be regarded as conclusive evidence of normative understanding, as we have argued, it can still count as confirming evidence for such understanding. In our view, this is more than a small shift in emphasis. It can lead to a more inclusive approach that is not restricted to measuring agents' reactions to a rule violation.

To illustrate this new proposal, consider a child that cries when she is put to bed and the lights are turned off. Suppose that Ronnie is old enough to notice a watch at the wall and that she observes that it is not yet 8 o'clock. When her Mum appears, presumably to turn off the lights, Ronnie does not immediately protest. She turns to the watch perhaps pointing at it - to pass on her observation that the time to go to sleep has not yet come. But when her Mum ignores this and turns off the light anyway, Ronnie starts to protest heavily.

This is a case, we believe, that helps us to see how normative understanding can manifest itself even prior to protest behaviour. The fact that Ronnie looks up to the watch when her Mum comes in, gives us good reason to say that she understands the normative force of the rule "When it is 8 o'clock, it is time to go to bed". Therefore, it does not matter that Ronnie might also protest when her Mum turns off the lights in accordance with the rule. It is her observing the watch that indicates her knowledge about when the lights should be turned off.

This example points in the direction of a quite different explanation of the origins of normative understanding. From very early on in their lives, children are confronted with authorities that tell them what to do or not to do: drink this, do not touch that, go to sleep, etc.

They come to understand such commands and know which circumstances prompt authorities to express them. At some point, however, they will find out that there are constraints for these commands to be justified. Even authorities cannot issue commands simply at their own will. There are rules that entitle them to do so depending on the circumstances. If it is 8 o'clock, Mum is entitled to turn off the lights and to command silence, not a minute earlier. Once children know that there are these constraints even for authorities, they are quick at finding out what these hidden rules are.

If we use the example of Ronnie as our real life example, two similarities with the 'daxing' studies are of particular importance. The first parallel is that Ronnie learns a rule that creates a social fact and that is therefore a constitutive rule in Searle's sense. It is not a naturally given fact that 8 o'clock is the right kind to go to bed. Without a rule that establishes this, 8 o'clock is neither the right nor the wrong time to go to bed. The second parallel is that in both cases the rules are not freely invented but authorized by an adult (The mother authorizes the rule of going to bed at 8 o'clock; the experimenter authorizes the 'daxing'-rule). When one carefully observes children in the 'daxing'- 
studies, one cannot fail to notice the special role of the experimenter who introduces the new game. Even if he later pretends to be inattentive, there are clear signs that he still figures as an authority to which children look up when a rule-violation occurs. It is known that children at this age are very sensitive to authorities, not only in the sense that they begin to test the authority of adults, but also in that they observe how authorities execute their power by rewarding or punishing (see Cummins 1996). It is therefore not surprising to see that children integrate these experiences into their play, and one obvious way to do this is to tell others how a specific game is to be played. That is why - when the experimenter retreats to a detached role, sometimes turning around and showing no interest in whether his instructions are observed or not children may feel inspired to take over this authoritative position. Since the experimenter is not on duty, it is now their job to enforce the rules they have learned from him. In this way one could also explain why slightly younger children around the age of 2 often refrain from showing such protest behaviour. They may not yet be ready to take on the position of an authority with respect to others and wait for the adult to interfere.

In view of these similarities, we suggest that children's reactions to rule-violations in game situations should be compared with their reactions to rule violations in real life contexts. In particular, one should pay attention to those reactions that indicate normative understanding independently of any protesting behaviour. In the case of Ronnie, her checking the watch provides such a reason. Can we find something similar also in the studies involving a conventional game? As long as we treat these games in isolation from real life issues, it may be difficult to attribute normative understanding independently from normative protest. But, we may connect real rewards with conventional games. Suppose that a candy is offered for a correct 'daxing'-move. Then a child who understands normativity knows that she is entitled to get a candy if her move was correct. In a case of injustice, when the reward is not given, we may therefore prompt a child to demonstrate that she acted in accordance with this rule. A child who knows that she deserves a candy may demonstrate this by repeating her move and thereby point out that she did everything correctly, e.g. using the pole, pushing the block, etc. We can hardly make sense of such a demonstration unless we interpret it as expressing a normative claim: "This is how I did it; this is correct, therefore I should get a reward."

Protest behaviour becomes relevant here only as a next step when the demonstration does not have the desired effect. This is again parallel to the case of Ronnie when her mum turns off the light despite having been made aware of the fact that it is not yet time to do so. In this context, the protesting behaviour does not indicate normative understanding, but confirms independently given evidence. The basic evidence is coming from behaviour that precedes a protesting response. Therefore, observations about when children begin to realize that authorities do not give idiosyncratic commands, but are themselves liable to socially implemented norms, should be included in future research.

\section{Summary and conclusion}

In this paper we focused on a recent line of research which suggests that even very young children can understand social norms quite independently of any moral context. 
We have looked at studies that take children's protesting behaviour as a reliable indicator of such an early normative understanding. In these studies children seem to protest when they realize that rule violations are not allowed or should not have happened. We agree that such an account often seems to provide the best explanation of children's behaviour. But we also found that serious methodological problems arise when one tries to substantiate this intuition. We therefore conclude that the protesting behaviour provides evidence for normative understanding not in isolation but only in conjunction with other independent data that still need to be provided.

Open Access This article is distributed under the terms of the Creative Commons Attribution 4.0 International License (http://creativecommons.org/licenses/by/4.0/), which permits unrestricted use, distribution, and reproduction in any medium, provided you give appropriate credit to the original author(s) and the source, provide a link to the Creative Commons license, and indicate if changes were made.

\section{References}

Behne, T., Carpenter, M., \& Tomasello, M. (2005). One-year-olds comprehend the communicative intentions behind gestures in a hiding game. Developmental Science, 8(6), 492-499. doi:10.1111/j.1467-7687.2005. 00440.x.

Bicchieri, C. (2006). The grammar of society: The nature and dynamics of social norms. New York: Cambridge University Press.

Brinck, I. (2014). Developing an understanding of social norms and games: emotional engagment, nonverbal agreement, and conversation. Theory and Psychology, 24(6), 737-754. doi:10.1177/0959354314555792.

Call, J., Hare, B. H., Carpenter, M., \& Tomasello, M. (2004). 'Unwilling' versus 'unable': chimpanzees' understanding of human intentional action? Developmental Science, 7(4), 488-498. doi:10.1111/j.14677687.2004.00368.x.

Casler, K., Terziyan, T., \& Greene, K. (2009). Toddlers view artifact function normatively. Cognitive Development, 24(3), 240-247. doi:10.1016/j.cogdev.2009.03.005.

Cummins, D. D. (1996). Evidence of deontic reasoning in 3- and 4-year-old children. Memory \& Cognition, 24(6), 823-829. doi:10.3758/BF03201105.

Kenward, B. (2012). Over-imitating preschoolers believe unnecessary actions are normative and enforce their performance by a third party. Journal of Experimental Child Psychology, 112(2), 195-207. doi:10.1016/j. jecp.2012.02.006.

Koenig, M. A., \& Echols, C. H. (2003). Infants' understanding of false labelling events: the referential roles of words and the speakers who use them. Cognition, 87, 179-208. doi:10.1016/S0010-0277(03)00002-7.

Legrain, L., Destrebecqz, A., \& Gevers, W. (2012). The role of goal-directed behavior in intention attribution in children. Journal of Experimental Child Psychology, 112(3), 351-359. doi:10. 1016/j.jecp.2012.01.004.

Marsh, H. L., Stavropoulos, J., Nienhuis, T., \& Legerstee, M. (2010). Six- and 9-month-old infants discriminate between goals despite similar action patterns. Infancy, 15(1), 94-106. doi:10.1111/j.1532-7078. 2009.00002.x.

Nucci, L. P. (2001). Education in the moral domain. Cambridge: University Press.

Philipps, W., Barnes, J. L., Mahajan, N., Yamaguchi, M., \& Santos, L. R. (2009). 'Unwilling' versus 'unable': capuchin monkeys' (Cebus apella) understanding of human intentional action. Developmental Science, 12(6), 938-945. doi:10.1111/j.1467-7687.2009.00840.x.

Rakoczy, H. (2008). Taking fiction seriously: young children understand the normative structure of joint pretence games. Developmental Psychology, 44(4), 1195-1201

Rakoczy, H., \& Tomasello, M. (2009). Done wrong or said wrong? Young children understand the normative directions of fit of different speech acts. Cognition, 113(2), 205-212. doi:10.1016/j.cognition.2009.07. 013.

Rakoczy, H., Warneken, F., \& Tomasello, M. (2008). The sources of normativity: young children's awareness of the normative structure of games. Developmental Psychology, 44(3), 875-881. doi:10.1037/00121649.44.3.875. 
Rakoczy, H., Brosche, N., Warneken, F., \& Tomasello, M. (2009). Young children's understanding of the context-relativity of normative rules in conventional games. British Journal of Developmental Psychology, 27(2), 445-456. doi:10.1348/026151008X337752.

Rossano, F., Rakoczy, H., \& Tomasello, M. (2011). Young children's understanding of violations of property rights. Cognition, 121(2), 219-227. doi:10.1016/j.cognition.2011.06.007.

Schmidt, M. F. H., Rakoczy, H., \& Tomasello, M. (2011). Young children attribute normativity to novel actions without pedagogy or normative language. Developmental Science, 14(3), 530-539. doi:10.1111/j. 1467-7687.2010.01000.x.

Schmidt, M. F. H., Rakoczy, H., \& Tomasello, M. (2012). Young children enforce social norms selectively depending on the violator's group affiliation. Cognition, 124(3), 325-333. doi:10.1016/j.cognition.2012. 06.004 .

Schmidt, M. F. H., Rakoczy, H., \& Tomasello, M. (2013). Young children understand and defend the entitlements of others. Journal of Experimental Child Psychology, 116(4), 930-944. doi:10.1016/j.jecp. 2013.06.013.

Searle, J. R. (1995). The construction of social reality. New York: The Free Press.

Tuncgenc, B., Hohenberger, A., \& Rakoczy, H. (2013). Early understanding of normativity and freedom to act in Turkish toddlers. Journal of Cognition and Development. doi:10.1080/15248372.2013.815622.

Turiel, E. (1983). The development of social knowledge: morality and convention. New York: Cambridge University Press.

Vaish, A., Missana, M., \& Tomasello, M. (2011). Three-year-old children intervene in third-party moral transgressions. British Journal of Developmental Psychology, 29(1), 124-130. doi:10.1348/ $026151010 \times 532888$.

Wyman, E., Rakoczy, H., \& Tomasello, M. (2009). Normativity and context in young children's pretend play. Cognitive Development, 24(2), 146-155. doi:10.1016/j.cogdev.2009.01.003. 